PAS SS

www.pasosonline.org

\title{
Reseña de Publicaciones
}

\author{
Choudhary, V. (2010). Island Tourism. \\ New Delhi: Centrum Press.
}

ISBN 9380540124

Silvia Marisa Rodrigues**

Universidade de Trás-os-Montes e Alto Douro (Portugal)

Enquanto geógrafo, Vikash Choudhary, o autor da obra "Island Tourism", dá-nos a conhecer uma perspetiva geográfica nos estudos de turismo. Perspetiva essa que se inicia com um breve apanhado dos principais autores e momentos marcantes do interesse e contribuição da disciplina por esta atividade, que à semelhança da maioria das ciências sociais, foi tardia, intensificando-se apenas pós II Guerra Mundial.

Depois de uma breve contextualização do crescimento da atividade turística no globo, o autor dá-nos a conhecer o estudo de caso no qual a obra se foca, concretamente as Ilhas da Baía, nas Honduras. Após uma descrição das características geológicas, naturais e culturais da ilha de Utila, parte das Ilhas da Baía, focando-se posteriormente na explanação do seu rico património pré-colombiano e principais mudanças sociais e culturais após a chegada do reino de Espanha e presença Britânica.

Esta descrição pretende por um lado, sublinhar a beleza natural destas ilhas, e por outro, a rica história e património que reúne, que alia a curiosidade por civilizações nativas, com a mística em torno da presença europeia, concretamente da atividade dos piratas dos séculos VII e VIII.

Atualmente, Choudhary refere a existência de uma estratificação social, assente numa discriminação racista baseada na cor da pele, que também se refletia no uso do espaço, concretamente na distribuição da população residente em bairros semi-segregadores, pelo menos até ao final do século XX.

Tal como em grande parte das caraíbas e do próprio continente americano, durante os primeiros séculos de ocupação europeia, também nas Bahamas a economia era baseada na agricultura e exploração de minerais. Utila baseava a sua economia na produção agrícola com colonos europeus que exploravam trabalho escravo local e africano. Mais recentemente, em particular desde a década de 1960, o turismo foi ganhando espaço como principal atividade económica e hoje, Utila. é totalmente dependente da mesma.

$\mathrm{O}$ autor destaca que nas primeiras décadas Utila era conhecida como uma ilha onde o consumo de álcool e drogas proliferavam, e com a crescente procura turística (em particular da Europa e América do Norte), também a oferta aumentou dramaticamente, em particular a hotelaria e a restauração, bem como, houve um grande investimento em infraestruturas (aeroportos, estradas, etc.).

Voltando a sua atenção para o impacto económico do turismo, o autor recorda que o crescimento económico implica, recorrentemente, fugas de capital da atividade em pequenos estados insulares, tendência que se agrava nas ilhas ou regiões periféricas aos grandes fluxos turísticos e, por conseguinte, aos investimentos em infraestruturas. A par dos impactos económicos, o autor recorda e descreve os impactos ambientais e sociais negativos mais comuns, como a gestão da água, a proteção da biodiversidade e a degradação costeira. Além destas questões, sublinha que, para atingir um desenvolvimento turístico sustentável, há também que considerar a questão política e legal. Defende que tal desenvolvimento deve ser alcançado através da implementação de planos estratégicos, de âmbito nacional e regional, baseados em práticas sustentáveis e cujo suporte assente num quadro legal claro e transparente. Acrescenta que estas práticas e ações devem ser alimentadas por investimento externo responsável,

E-mail: antroposilvia@hotmail.com 
que não hipoteque os potenciais benefícios e dividendos para o destino e, simultaneamente, reforçadas pela capacitação e profissionalização dos recursos humanos, investimento em tecnologia e criação de infraestruturas. O desenvolvimento turístico sustentável depende, ainda, de um último ingrediente que, recentemente, tem ganhado vulto. Falamos da cooperação regional entre destinos, cujo propósito visa colmatar limitações e constrangimentos comuns. Uma cooperação que se estende às componentes da promoção e oferta turística. Isto é o equivalente a dizer que envolve o setor privado e a sociedade civil (comunidades e organizações não governamentais).

A abertura ao turismo internacional, mesmo quando planeado, exige constante monitorização e adaptabilidade, na medida em que se posiciona como uma atividade permeável a flutuações e tendências da procura. Entre estas, o autor destaca o caso dos mochileiros e dos "espanhóis" na ilha de Utila. Os primeiros surgem como exemplo de um tipo de turismo cuja contribuição para a economia local é residual e com um impacto negativo ao nível social, muito por retirar oportunidades de emprego aos locais; algo que os segundos, relativamente aos nativos do continente, também faziam, discriminando os insulares e aumentando a criminalidade.

Choudhary retoma a questão anterior dos impactos do turismo fazendo alusão ao seu estudo de caso e, assim, destaca (i) o rápido crescimento da população, que forçosamente a descaracteriza, (ii) o aumento do fosso entre ricos e pobres, que resulta da distribuição desigual dos dividendos económicos, (iii) a descaracterização urbana e arquitetónica da ilha e (iv) as mudanças físicas da paisagem natural.

De Utila para a ilha de Kangaroo na Austrália, após uma breve caracterização geográfica e da composição da fauna e da flora, cuja utilização serve para justificar a aposta no ecoturismo e no turismo de natureza, o autor apresenta-nos alguns dos desafios da atividade turística. Entre estes, o difícil equilíbrio entre a manutenção da proteção natural da ilha e o desenvolvimento de um turismo sustentável, face a potenciais novos constrangimentos como o aumento do risco de incêndio, a caça ou o desaparecimento de espécies. Equilíbrio este que procurou ser atingido através de amplas políticas diretas, apoiadas pelas comunidades locais, que garantem tanto o financiamento dos parques e áreas protegidas, como oportunidades económicas para o setor privado e residentes.

O autor infere que, em resultado de questionários aplicados pelo próprio, o ecoturismo é definido de forma genérica, não se distinguindo de outros tipos como turismo alternativo. Nesse sentido, o livro Island Tourism dedica algumas páginas à sua definição, avaliação da capacidade e importância e, por último, aos passos necessários para a sua aplicação. Aproveita, ainda, para destacar o sucesso deste tipo de turismo para a conservação da natureza em vários países da América Latina e Caraíbas, identificando, simultaneamente, alguns exemplos de insucesso, motivados pela sobrecarga de visitantes e ausência de um planeamento adequado.

Já na ilha de Redang (Malásia), o autor aborda a utilização da água segundo duas perspetivas distintas: a religiosa e a empresarial, contrapondo o uso racional da água num contexto islamizado e nos resorts turísticos. Os seus resultados apontam para uma disparidade de discursos sobre o uso desse recurso entre residentes, trabalhadores e gestores/diretores dos hotéis. Choudhary pretende demonstrar como as práticas religiosas (e.g. a ablução no Islão) competem diretamente com o uso racional da água, colocando ênfase nas dinâmicas culturais e religiosas, e não apenas na questão do consumo quotidiano. Conclui-se, no seguimento, que a pressão da atividade turística deve ter em consideração estas questões, isto quando se pretende garantir um envolvimento e aceitação plenos por parte das comunidades locais.

Falar de uso e gestão de recursos hídricos e da atitude de residentes é regressar à questão da sustentabilidade, daí que o foco seja direcionado também para a definição de sustentabilidade mas, sobretudo, para os indicadores que a monitorizam. $\mathrm{O}$ autor apresenta, então, 10 princípios para o turismo sustentável, propondo que estes sejam medidos recorrendo a múltiplos indicadores específicos. Consideramos que o problema central da implementação do turismo sustentável não está relacionado com a ausência de propostas como esta. A questão nuclear prende-se, antes, com a viabilidade das propostas, dado que grande parte dos países em desenvolvimento, regiões periféricas e territórios insulares são permeáveis à falta de condições económicas, técnicas e políticas, que se constituem como as bases para a implementação ótima de práticas sustentáveis. Choudary acaba, assim, por chegar a esta mesma conclusão quando reflete sobre as dificuldades em atingir um desenvolvimento turístico sustentável em territórios insulares. Deste modo, apresenta um conjunto de políticas, capazes de contrariar as dificuldades identificadas, baseadas no (i) envolvimento das comunidades, (ii) aposta na tecnologia, (iii) desenvolvimento dos transportes e acessibilidades, (iv) diferenciação e promoção da oferta e (v) práticas de gestão ambiental. Apesar de nenhuma destas propostas se constituir como inovadora, o autor acaba por sublinhar a sua importância, destacando-as no seu estudo de caso sobre a ilha de Antígua. 
Centrando-se no caso da Indonésia, cuja aposta política no turismo internacional teve início, apenas, a partir da década de 1990, o destaque recai na mais recente aposta no ecoturismo. Usando as ilhas de Bali e de Lombok como exemplos desse intento, Choudhary inicia um debate em torno das possíveis soluções para que o turismo sustentável se torne uma realidade. Regressando às origens do conceito de desenvolvimento e de turismo como um meio de modernização, o autor expõe as debilidades desse modelo e introduz algumas propostas recentes, baseadas num desenvolvimento turístico alternativo, grosso modo, assente nos princípios de sustentabilidade e numa perspetiva holística sobre todo o processo. Uma forma de o alcançar, argumenta, seria assumir o processo reconhecendo a necessidade de estabelecer compromissos e cedências entre os potenciais benefícios e malefícios da atividade turística. Compromissos esses que seriam estabelecidos entre todos os stakeholders, num espírito de boa governança o que, por seu turno, exige estabilidade política de forma a garantir segurança e a atrair investimento externo. Se o objetivo passa pelo desenvolvimento turístico sustentável, o autor argumenta que o ecoturismo pode, de facto, ser uma possível e desejável proposta. Todavia, usando múltiplos estudos de caso no sudeste da Ásia, conclui que o ecoturismo parece estar condenado a apenas um nicho de mercado, uma vez que o aumento do fluxo turístico implica maior pressão e deterioração dos recursos naturais como a paisagem, a fauna ou a flora. Mesmo com um menor número de turistas, estes territórios, em particular as áreas e parques protegidos, podem beneficiar em larga escala, uma vez que os dividendos económicos e a mediatização dos mesmos podem contribuir positivamente para a sua conservação. $\mathrm{O}$ argumento proposto posiciona o ecoturismo como uma ferramenta para a conservação e envolvimento das comunidades na atividade turística e não como "uma bala mágica".

Ainda no desenvolvimento do livro, o autor introduz-nos um fator externo central para futuro do turismo e, de certa forma, para a própria humanidade, e que está relacionado com os impactos das alterações climáticas, especificamente em Pequenos Estados Insulares em Desenvolvimento (PEID). Como vimos, os PEID estão muito dependentes da atividade turística, sendo que esta é, reconhecidamente, uma das grandes contribuidoras para o agravamento das alterações climáticas. Como tal, estes estados veem-se como que obrigados a desenvolver mecanismos e dinâmicas que consigam superar estas dificuldades, antes do ponto de não retorno. Dinâmicas que podem passar por uma agenda comum e integrada que reduza a pegada ecológica do turismo, nomeadamente através da introdução de políticas limitadoras dos impactos negativos do turismo, tal como o investimento em novas tecnologias e energias renováveis, a capacitação e envolvimento crescente das comunidades locais e a proteção do património cultural.

Considerando, então, o desenvolvimento económico destes destinos turísticos e tendo em conta características comuns aos mesmos, como o isolamento geográfico, os recursos limitados ou a população reduzida, torna-se clara a dificuldade acrescida em alcançar esse desenvolvimento. É neste contexto que, de acordo com o autor, o turismo assume um papel central nas ilhas do Pacífico, em particular em Okinawa e Havai. Assim, com o intuito de alcançar esse crescimento, destaca-se a importância de um desenvolvimento sustentável que harmonize os aspetos socioculturais, económicos e ambientais, beneficiando o espaço geográfico e os residentes. Todavia, o autor não descura os também constrangimentos económicos, ambientais e socioculturais que estão associados, assumindo como exemplo a falta de bens locais que obriga à importação de bens substitutos, como forma de cativar o turista, que resulta num dividendo externo e na diminuição exponencial da receita para destino. A este, somar-se-ão outros constrangimentos, nomeadamente ambientais, que vão desde a limitação a nível de energia ou à quantidade de água disponível, passando pela poluição resultante do uso inadequado dos recursos e à diminuta capacidade de tratamento dos resíduos.

Tocando ainda nos constrangimentos socioculturais, a par dos benefícios, tais como melhoria das infraestruturas e fornecimento de água, ou do estímulo para preservação do folclore local, tradições e arte, surge o possível prejuízo da comunidade residente. Segundo Choudhary, o ciclo de vida de um destino turístico compreende cerca de 50 a 75 anos, divididos por quatro fases: exploração, desenvolvimento, maturação e declínio. Retomando as ilhas do Havai e Okinawa como exemplo, que se encontram no terceiro estágio, sublinha-se a necessidade da implementação de novas medidas que prolonguem o seu ciclo e promovam um rejuvenescimento do destino.

Nestes exemplos, é atribuído, ao governo, um papel fulcral no que ao planeamento, análise de mercado e do produto diz respeito, numa tentativa de criar e recriar novas atividades e atrações, capazes de competir com a oferta de destinos concorrentes. Assim, destaca a importância do papel do planeamento e das políticas públicas para o desenvolvimento do turismo nestas ilhas, através de processos agregadores dos interesses públicos, privados e da sociedade civil.

O livro Island Tourism tem como principais contributos a capacidade de apresentar inúmeros exemplos de estudos de caso realizados pelo autor em Estados insulares por todo o mundo, fornecendo 
uma perspetiva global que permite encontrar diversos aspetos comuns. Entre estes, os processos que conduziram ao turismo internacional nestes territórios, os seus impactos positivos e negativos. É atribuída particular atenção à questão da sustentabilidade e à conservação da natureza e do património cultural. A visão da geografia sobre estas questões é apresentada com clareza e a sua presença é desejável, dada a influência e postura dominadora de outras disciplinas sobre a temática do turismo. É, particularmente evidente, o interesse e a postura de Vikash Choudhary face ao desenvolvimento turístico, em particular o posicionamento ideológico, que defende e projeta, sobre o ecoturismo e o respetivo papel no futuro do turismo mundial. Talvez a grande debilidade desta obra seja a dispersão e sobreposição de argumentos e ideias. O leitor irá deparar-se com uma certa repetição e dispersão dos argumentos, que resulta do facto deste livro ser uma montagem de vários artigos do autor. Crê-se que tal aspeto acaba por enfraquecer o contributo do mesmo e conduzir a uma leitura desarticulada dos estudos de caso, e resultados, de enorme interesse para quem estuda este tema. 